\title{
DEVELOPMENT AND CHARACTERIZATION OF IN SITU GEL OF XANTHAN GUM FOR OPHTHALMIC FORMULATION CONTAINING BRIMONIDINE TARTRATE
}

\author{
VAZIR ASHFAQ AHMED ${ }^{1 *}$, DIVAKAR GOLI ${ }^{2}$ \\ ${ }^{1}$ Department of Pharmaceutics, MMU College of Pharmacy, Ramanagara, Karnataka, India. ${ }^{2}$ Department of Pharmaceutics, Acharya and \\ BM Reddy College of Pharmacy, Bengaluru, Karnataka, India. Email: mail2vazir@gmail.com
}

Received: 09 February 2018, Revised and Accepted: 11 April 2018

\begin{abstract}
Objective: The goal of this study was to develop and characterize an ion-activated in situ gel-forming brimonidine tartrate, solution eye drops containing xanthan gum as a mucoadhesive polymer.

Method: Sol-gel formulation was prepared using gellan gum as an ion-activated gel-forming polymer, xanthan gum as mucoadhesive agent, and hydroxypropyl methyl cellulose (HPMC E50LV) as release retardant polymer. Phenylethyl alcohol is used as preservatives in borate buffer. The $2^{3}$ factorial design was employed to optimize the formulation considering the concentration of gelrite, xanthan gum and HPMC as independent variables, gelation time, gel strength, and mucoadhesive force $(\mathrm{N})$. Gelation time, gel strength, mucoadhesive force $(\mathrm{N})$, viscosity (cP) and in vitro percentage drug release were chosen as dependent variables. The formulation was characteristics for $\mathrm{pH}$, clarity, isotonicity, sterility, rheological behavior, and in vitro drug release, ocular irritation, and ocular visualization.
\end{abstract}

Result: Based on desirability index of responses, the formulation containing a concentration of gelrite (0.4\%), xanthan gum (0.21\%), and HPMC (HPMC E50 (0.24\%) was found to be the optimized formulation concentration developed by 23 factorial design. The solution eye drops resulted in an in situ phase change to gel-state when mixed with simulated tear fluid. The gel formation was also confirmed by viscoelastic measurements. Drug release from the gel followed non-fickian mechanism with $88 \%$ of drug released in $10 \mathrm{~h}$, thus increased the residence time of the drug.

Conclusion: An in situ gelling system is a valuable alternative to the conventional system with added benefits of sustained drug release which may ultimately result in improved patient compliance.

Keywords: Xanthan gum, Hen’s egg test-chorioallantoic membrane test, Brimonidine tartrate.

(C) 2018 The Authors. Published by Innovare Academic Sciences Pvt Ltd. This is an open access article under the CC BY license (http://creativecommons. org/licenses/by/4. 0/) DOI: http://dx.doi.org/10.22159/ajpcr.2018.v11i7.25221

\section{INTRODUCTION}

Drug activity is a result of the molecular interaction(s) in certain cells; it is, therefore, easily deduced that it is necessary for the drug to reach the site of action following administration at sufficient concentrations. The conventional drug delivery such as suspension, ointment, and solution shows drawbacks such as binding with the lachrymal proteins, drainage of the instilled solutions, lachrimation and tear turnover, limited corneal area, and poor corneal metabolism, and non-productive absorption. For the therapeutic treatment of most ocular problems, the topical administration seems to be the preferred route. However, the conventional ophthalmic solutions exhibit poor bioavailability and therapeutic response due to the rapid pre-corneal elimination of the drug. This is challenged by proper designing of $i n$ situ gel systems, which are instilled as drops into the eye and undergo a solgel transition in the cul-de-sac [1-3]. A further approach to optimize the ocular dosage form is the incorporation of the mucoadhesive polymers. Interactions of suitable natural and synthetic polymers with the mucus layer of eye tissues increase the precorneal residence time of the preparation. The intimate contact may result in high drug concentration in the local area and hence high drug flux through the absorbing tissue [4-6].

The aim of this work is to formulate ocular in situ gelling systems using ion activated polymer containing Brimonidine tartrate (BT) and to evaluate the performance of the prepared in situ gelling system.

\section{METHODS}

The following materials are used for the study; BT (FDC Limited Mumbai), Gelrite (Applied Biosciences [KELCO], Mumbai), Xanthan gum (Kajoba Gums, Mumbai), Hydroxypropyl methyl cellulose (HPMC) E50 LV (LOBA chemicals, Mumbai), and Rhodamine B (Amrithal Chemuax Pvt Ltd., Mumbai). All other chemicals were of analytical grade.

\section{Animals}

With the approval of Institute Animal Ethical Committee (IAEC/ ABMRCP/PR/2012-2013/19), the study was performed, and the protocol was approved as per the CPCSEA guidelines. Albino rabbits (Newzeland white rabbit) were used as test species. The right eye was designated as control and left one as test eye. In the lower conjunctival cul-de-sac, two drops of the formulation were instilled, and for few seconds after installation, eyelids were held together, and later normal blinking was allowed.

\section{Analytical methods}

Scanning for drug absorption $\left(\lambda_{\text {Max }}\right)$ using double beam spectrophotometer

BT was scanned in $7.4 \mathrm{pH}$ phosphate buffer $(10 \mu \mathrm{mg} / \mathrm{ml})$ using double beam ultraviolet (UV)-visible spectrophotometer (UV-1700 Pharma Spec/Shimadzu Japan) in a wavelength range of 200$400 \mathrm{~nm}$.

Development of UV spectrophotometric method for analysis of BT A final concentration of $3,6,9,12,15,18$, and $21 \mu \mathrm{g} / \mathrm{ml}$ was prepared using $7.4 \mathrm{pH}$ phosphate buffer. The absorbance of each concentration was measured at $248 \mathrm{~nm}$ using UV spectrophotometer against blank. The standard curve was obtained by plotting absorbance versus concentration in $\mu \mathrm{g} / \mathrm{ml}$. 
In vitro gelation behavior studies of polymers with simulated tear fluid (STF)

Concentrations of gelrite, xanthan gum alone and in combinations ranging from 0.1 to $1 \%$ were prepared and evaluated for in vitro gelling studies. The gelling time of formulations of different batches was determined by placing 1 or 2 drops of polymeric solution in a vial containing $2 \mathrm{ml}$ of freshly prepared STF $(7.4 \mathrm{pH})$ equilibrated at $37^{\circ} \mathrm{C}$. The gel formation was visually observed and time for gelation was noted [7].

\section{Procedure for preparation of in situ gels}

Added required quantity of gelrite polymer to the borate buffer solution and heated to about $70^{\circ} \mathrm{C}$ until it is completely dissolved. To prepared gelrite solution required quantity of xanthan gum was added and stirred well on a magnetic stirrer with slight heating. To the above-prepared gelrite/mucoadhesive solution, required quantity of drug $(0.2 \%$ Brimonidine) for their respective batches was added with continuous stirring until it is thoroughly mixed. HPMC E50 LV and phenylethyl alcohol were added and stirred on a magnetic stirrer. $\mathrm{pH}$ was checked and adjusted with buffer. The prepared in situ gel was filled in glass vials and closed with closures, capped with aluminum caps and sterilized by autoclaving.

\section{Design of experiments employing factorial design}

Various batches of formulations were prepared by employing $2^{3}$ factorial designs. The independent variables chosen were concentrations of gelrite, HPMC E50 LV, and xanthan gum. The independent variables levels were gelrite $(0.2,0.4)$, xanthan gum $(0.2,0.4)$, and HPMC E50 LV $(0.2,0.4)$. Levels were assigned after carrying out different trial studies on concentration ranging from 0.1 to $1 \%$ for the responses. Gelation time, gel strength, and mucoadhesive force viscosity in centipoise (cP), and in vitro percentage drug release was taken as the response parameters and are categorized as dependent variables.

\section{Optimization data analysis and model-validation}

ANOVA was used to establish the statistical validation of the polynomial equations generated by Design Expert ${ }^{\circledR}$ software (version 8.0, Stat-Ease Inc., Minneapolis, MN). Fitting a multiple linear regression model to a $2^{3}$ factorial design gave a predictor equation which was a first-order polynomial, having the form:

$$
\mathrm{Y}=\mathrm{b}_{\mathrm{o}}+\mathrm{b}_{1} \mathrm{X}_{1}+\mathrm{b}_{2} \mathrm{X}_{2}+\mathrm{b}_{3} \mathrm{X}_{3}+\mathrm{b}_{12} \mathrm{X}_{1} \mathrm{X}_{2}+\mathrm{b}_{13} \mathrm{X}_{1} \mathrm{X}_{3}+\mathrm{b}_{23} \mathrm{X}_{2} \mathrm{X}_{3}+\mathrm{b}_{123} \mathrm{X}_{1} \mathrm{X}_{2} \mathrm{X}_{3}
$$

Where $\mathrm{Y}$ is the measured response associated with each factor level combination; $b_{0}$ is an intercept representing the arithmetic average of all quantitative outcomes of eight runs; $b_{1}$ to $b_{123}$ are regression coefficients computed from the observed experimental values of $\mathrm{Y}_{\mathrm{X}} \mathrm{X}_{1}$, $\mathrm{X}_{2}$, and $\mathrm{X}_{3}$ are the coded levels of independent variables. The terms $\mathrm{X}_{1} \mathrm{X}_{2}$, $\mathrm{X}_{2} \mathrm{X}_{3}$, and $\mathrm{X}_{1} \mathrm{X}_{3}$ represent the interaction terms.

\section{Fourier transform infrared (FTIR) study [8]}

$\mathrm{BT}$ and the physical mixture containing pure drug and polymers were scanned (8400S/Shimadzu Japan) in the wavenumber region of 400$4000 / \mathrm{cm}$ using $\mathrm{KBr}$ pellet method [8].

\section{Measurement of gel strength}

A $50 \mathrm{~g}$ of prepared gel $\left(25\right.$ formulations:7 STF maintained at $37^{\circ} \mathrm{C}$ ratio) was placed in a $100 \mathrm{ml}$ graduated cylinder. A probe was placed on the gel, and a weight of $15 \mathrm{~g}$ was placed on the probe. The probe was allowed to penetrate a fixed distance of $5 \mathrm{~cm}(30 \mathrm{ml})$ and the time it tooks to travel the distance was recorded [9].

\section{Mucoadhesive strength by modified balance method}

The mucoadhesive strength was measured using a modified two-arm balance. The biological membrane was fixed to the inverted bottom surface of a $100 \mathrm{ml}$ beaker; this was then placed in a larger beaker with membrane facing upward. STF (7.4) was added to the larger beaker up to the upper surface of the gastric mucosa such that the media remains just moistened with the media. Accurately weighted 1gram of the preformed gel was put on the inverted beaker and was placed under the bottom of stainless steel pan. A preload of $50 \mathrm{~g}$ was placed on the pan for $5 \mathrm{~min}$ to establish adhesion bonding between gel and biological membrane. Preload was removed from the pan, and another beaker was placed on to another side of the pan. The addition of water was stopped when the other side of the pan got detached from the membrane. The mass, in grams required to detach the pan from membrane gave the measure of mucoadhesive strength [10].

\section{Rheological studies}

The viscosity of the instilled ophthalmic solution is an important factor in determining residence time of the drug in the eye. Rheological behaviors of different ratio of in situ gelling polymeric solutions were evaluated on a Brook Field's DV-I+ model. Based on the viscosity range and torque the spindles were selected. The temperature was maintained by circulating water at $37^{\circ} \mathrm{C}$ across the sampler. For gelation, the sample solution was mixed with STF in $25 \mu \mathrm{l}: 7 \mu \mathrm{l}$ ratio. The angular viscosity was increased gradually from 10 to $100 \mathrm{rpm}$ with an equal wait for each rpm. The viscosity measured at both the conditions was plotted (angular viscosity versus the angular velocity (rpm) [11].

\section{In vitro release studies}

The in vitro drug release was studied using a USP rotating paddle apparatus. STF 7.4 maintained at $37^{\circ} \mathrm{C}$ was used as the medium. The paddle speed was set to $50 \mathrm{rpm} .3 \mathrm{ml}$ of the formulation was placed in a dialysis tube with cellophane membrane covered cells, and it was placed such that it touches the diffusion medium. The drug samples were withdrawn at the interval of $1 \mathrm{~h}$ for a period of $10 \mathrm{~h}$ from the medium and were analyzed by UV spectrophotometer at their respective wavelength using STF as blank. The cumulative percentage drug release and release kinetics were evaluated [12].

PH: The $\mathrm{pH}$ of the prepared in situ gelling system was measured using $\mathrm{pH}$ meter.

\section{Optical clarity studies}

Optical clarity of solutions/gels was carried out using UV visible spectrophotometer (Shimadzu, 1700 Japan) against STF (7.4) as the reference. The formulation was placed in a glass cuvette containing STF, care was taken to avoid air bubbles, and the cuvette was inverted up and down to confirm gel formation. Transmission of light was measured at $580 \mathrm{~nm}$, and it was kept constant for all batches [13]

\section{Isotonicity evaluation}

Sheep blood was obtained from the slaughterhouse in a container containing $4 \%$ of Tris-sodium citrate. Few drops of the formulation were taken china dish and added few drops of blood and gently shaken for mixing blood and formulation. The blood sample was drawn from the china dish into red blood cell (RBC) pipette up to 0.5 mark and further diluted with RBC diluting fluid. On the hemocytometer, a drop of sample was placed and covered with a coverslip on the counting chamber. By placing the counting chamber on the mechanical stage of the microscope, the cells were observed. The tonicity of the formulation was checked under the microscope $(45 x)$ for the effect on RBC for cremation or swelling and bursting [14].

\section{Test for sterility}

According to pharmacopeias, the sterility testing is intended for detecting the presence of viable forms of microorganisms in the pharmaceutical preparations.

\section{Method of direct transfer}

Tests for sterility were performed for fungi, aerobic, and anaerobic bacteria using soybean casein digest media and fluid thioglycollate media. According to Indian pharmacopoeia for ophthalmic preparation, if the number of items in a Batch is not more than 100 containers, the minimum numbers of item recommended to be tested are two containers. Two autoclaved glass vials each containing $10 \mathrm{ml}$ of the formulation (placebo) were used. This study was carried out to obtained sterile preparation, which can be instilled into rabbit eyes to understand the ocular behavior and visualization of the formulation when it comes in contact with the lachrymal fluid of eye [19]. 
Growth promotion (positive control) test

One culture tube containing $10 \mathrm{ml}$ of sterile media was inoculated with a sterile loop full of micro-organisms and incubated as per the specified conditions. It is labeled as a "positive control."

\section{Sterility (negative control) test}

Uninoculated sterile culture tube containing $10 \mathrm{ml}$ each for fluid thioglycollate media and one for soybean casein digest medium were taken. These were incubated as per the specified conditions. It is labeled as a "negative control."

\section{Test for aerobic and anaerobic bacteria}

Two culture tubes containing $10 \mathrm{ml}$ each of sterile fluid thioglycollate media were labeled. $1 \mathrm{ml}$ of the formulation was introduced to the depth of culture tube with the help of sterile syringe aseptically and labeled as depth $\mathrm{D}^{*}$ (for anaerobic). To another culture tube of sterile fluid thioglycollate media, $1 \mathrm{ml}$ of the formulation was introduced on to the surface of the culture media with the help of sterile syringe aseptically. The tube labeled as surface $S^{*}$ (for aerobic). The four tubes (positive, negative, and two-labeled test tubes) were incubated at $35^{\circ} \mathrm{C}$ for 14 days.

\section{Test for fungi}

Three sterilized culture tubes containing $10 \mathrm{ml}$ each of sterile soybeancasein digest media were taken. The tube labeled as a positive control was inoculated with a sterile loop full of viable microorganism, Candida albicans aseptically. Uninoculated culture tube was labeled as a negative control. $1 \mathrm{ml}$ of the formulation was added to the culture tube aseptically and labeled as the test. Three tubes were incubated at $25^{\circ} \mathrm{C}$ for 14 days.

\section{Ocular irritation test (hen's egg test-chorioallantoic membrane [HET-CAM] test)}

\section{Procedure}

In this test, $9^{\text {th }}$ day incubated white leghorn chicken eggs weighing between 50 and $60 \mathrm{~g}$ were selected. Marked air cell of the egg and placed it on the egg cup holder. With the help of a dentist blade, a window $(2 \times 2 \mathrm{~cm})$ was made on the egg air cell, pared off the outer shell. With the forceps, the outer membrane was removed, and care was taken to ensure that the CAM was not injured. About $0.3 \mathrm{ml}$ of formulation, positive control, and the negative control was applied directly onto the CAM surface and left in contact for $5 \mathrm{~min}$. Monitored and recorded the time for the appearance of each of the noted endpoints in minutes.

\section{Positive Control}

$0.3 \mathrm{~mL}$ of $0.1 \mathrm{~N} \mathrm{NaOH}$ to provide a baseline for the assay endpoints negative control: $0.3 \mathrm{ml}$ of $0.9 \% \mathrm{NaCl}$ solution to provide a baseline for the assay endpoints. Treatment: $0.3 \mathrm{~mL}$ of formulation on the CAM of the $9^{\text {th }}$ day egg. Observed the reactions on the CAM were observed for a period of $300 \mathrm{~s}(0.5 \mathrm{~min}, 2 \mathrm{~min}$, and $5 \mathrm{~min})$. Monitored and recorded the time for the appearance of each of the noted endpoints, in minutes.

\section{End points}

Observed endpoints are hemorrhage (bleeding from the vessels), vascular lysis (blood vessel disintegration), and coagulation (intra- and extra-vascular protein denaturation) on CAM $[20,21]$.

Ocular visualization of in situ gels with fluorophores (rhodamine B) Two drops of the sterile formulation with rhodamine B (0.01\%) were instilled into the rabbit eye. (One eye served as control and another eye as the test). The eyelids were held close for few second; the in situ gel so formed was visualized [22].

\section{RESULTS AND DISCUSSION}

Compatibility study of drug with different polymers using FT-IR Spectrophotometer: FTIR spectra were measured using FTIR spectroscopy (8400S/Shimadzu Japan) to determine the possible interactions between drug and polymers. The pure drug, polymers, and drug-polymer physical mixture were scanned from 4000 to $400 / \mathrm{cm}$ in Shimadzu FTIR 8400S spectrophotometer using KBr pellet method. The IR spectrums of the physical mixture were compared with those of drug and polymers and matching was done to detect appearance or disappearance of peaks (Table 1).

$2^{3}$ Factorial design was employed to under the factors that are critical for the response. The main effect study and interaction study of factors reveals that concentration of the polymer plays as important role in viscosity, mucoadhesive study and percentage drug release in the development of formulation (Tables 2 and 3 ).

\section{Polynomial equation coded factor}

\section{Gelation time (s)}

As shown in the equation, the factors have a significant effect on the gelation time. The variables such as concentration of gelrite (A), xanthan gum (B), and HPMC E50 LV (C) have a negative effect on the gelation time. That means an increase in the concentration of GL, KC, and HP will show reduced gelation time. The higher concentration level of gelrite and xanthan gum gave the low value of gelation time at all level (Table 4).

\begin{tabular}{lllll}
\hline Growth promoting organism & $\begin{array}{l}\text { Incubation } \\
\text { temperature }\end{array}$ & Type & $\begin{array}{l}\text { Quantity of culture } \\
\text { medium [17] }\end{array}$ & $\begin{array}{l}\text { Quantity of test } \\
\text { sample [18] }\end{array}$ \\
\hline E. coli $[15,16]$ ATCC 8739 & $35^{\circ} \mathrm{C}$ & Aerobic and anaerobic & $10 \mathrm{ml}$ & $1 \mathrm{ml}$ \\
Candida albicans ATCC 10231 & $25^{\circ} \mathrm{C}$ & Fungi & $10 \mathrm{ml}$ & $1 \mathrm{ml}$ \\
\hline
\end{tabular}

E. coli: Escherichia coli

Table 1: Comparison of functional groups peaks wave no $\left(\mathrm{cm}^{-1}\right)$ of BT samples testing by FTIR spectroscopy

\begin{tabular}{llll}
\hline Functional group & $\begin{array}{l}\text { Frequency } \\
\text { range }\left(\mathbf{c m}^{-\mathbf{1}} \mathbf{)}\right.\end{array}$ & $\begin{array}{l}\text { Observed frequencies } \\
\text { of pure drug }\end{array}$ & $\begin{array}{l}\text { Reported frequencies of drug in the physical } \\
\text { mixtures BGXH* }\end{array}$ \\
\hline N-H stretching & $3500-3300$ & 3400 & 3435 \\
Aromatic C-H stretching & $3100-3000$ & 3000 & 2983 \\
N-H bending & $1640-1550$ & 1593 & 1593 \\
C=O stretching & $1740-1690$ & 1729 & 1731 \\
-C=N- stretching & $1680-1620$ & 1652 & 1651 \\
C=C stretching & $1600-1400$ & 1486 & 1486 \\
C-O stretching & $1300-1000$ & 1300 & 1300 \\
OH bending & $1085-1050$ & 1072 & 1073 \\
C-Br stretching & $600-500$ & 583 & 600 \\
\hline
\end{tabular}

BGXH*: Brimonidine tartrate with gelrite, xanthan gum and HPMC E50LV. BT: Brimonidine tartrate, FTIR: Fourier transform infrared, HPMC: Hydroxypropyl methyl cellulose 


\section{Gel strength}

As shown in the equation, the factors have a significant effect on the gel strength. The variables such as concentration of gelrite (A), xanthan gum (B), and HPMC E50 LV (C) have a positive effect on gel strength. That means an increase in the concentration of $A, B$, and $C$ will show an increase in gel strength (Table 5).

\section{Mucoadhesive force}

As shown in the equation, the factors have a significant effect on the mucoadhesive force. The variables such as concentration of gelrite (A) xanthan gum (B) and HPMC E50 LV (C) have a positive effect on mucoadhesive force. That means an increase in the concentration of $A$, $\mathrm{B}$, and $\mathrm{C}$ will show increase in mucoadhesive force (Table 6).

\section{Viscosity before gel}

As shown in the equation, the factors have a significant effect on the viscosity. The variables such as concentration of gelrite (A), xanthan

Table 2: Experimental layout of factors

\begin{tabular}{llll}
\hline \multirow{2}{*}{ Batch code } & \multicolumn{2}{l}{ Polymers (\%) } & \\
\cline { 2 - 4 } & Gelrite & Xanthan gum & HPMC E50 \\
\hline F1 & 0.4 & 0.4 & 0.2 \\
F2 & 0.2 & 0.2 & 0.2 \\
F3 & 0.4 & 0.4 & 0.4 \\
F4 & 0.2 & 0.2 & 0.4 \\
F5 & 0.2 & 0.4 & 0.4 \\
F6 & 0.4 & 0.2 & 0.2 \\
F7 & 0.4 & 0.2 & 0.4 \\
F8 & 0.2 & 0.4 & 0.2 \\
\hline
\end{tabular}

HPMC: Hydroxypropyl methyl cellulose gum (B), and HPMC E50 LV (C) have a have a positive effect on the viscosity. That means an increase in the concentration of $\mathrm{A}, \mathrm{B}$, and $\mathrm{C}$ will show increase viscosity (Table 7).

Cumulative drug release (\%) $10^{\text {th }} \mathrm{h}$ : As shown in the equation, the factors have a significant effect on cumulative drug release. At $1^{\text {st }} \mathrm{h}$ the variables such as xanthan gum (B) and HPMC E50 LV (C) have a negative effect on drug release. Which means that $B$ and $C$ have drug release controlling capacity? Whereas $\mathrm{A}$ at $1^{\text {st }}$ his not able control the drug release. Hence, A has shown a positive effect. AB and AC have shown a negative effect.

At $10^{\text {th }} \mathrm{h}$, all polymers $\mathrm{A}, \mathrm{B}$, and $\mathrm{C}$ and their combination $\mathrm{AB}$ has shown the negative effect which indicates that increase in polymer concentration will reduce the percentage drug release. Which is significant for drug release? (Table 8).

Interaction studies of factors reveal that concentration of xanthan gum, gelrite, and HPMC E50 LV is critical factors. The concentration of xanthan gum should be carefully chosen to have proper mucoadhesive property. Desirability approach was utilized by setting a target to have a formulation which will have required properties of gelation time, gel strength, mucoadhesive property, viscosity, and in vitro drug release (Table 9).

These were further evaluated for the optimization responses (gelation time, gel strength, mucoadhesive force $(\mathrm{N})$ viscosity $(\mathrm{cP})$, and in vitro percentage drug release) to confirm the validity of optimization process, formulations exhibiting desirability like 0.903 , close to 1 were selected as optimized formulation (Fig. 1).

The statistically optimized formulation fulfilled all the physicochemical criteria. The observed values were in close agreement with the model predictions. The relative errors (\%) between the predicted and

Table 3: Experimental layout of responses

\begin{tabular}{|c|c|c|c|c|c|c|}
\hline Batch code & $\begin{array}{l}\text { Gelation } \\
\text { time } \pm \mathrm{SD}^{*}(\mathrm{~s})\end{array}$ & $\begin{array}{l}\text { Gel strength } \pm \mathrm{SD}^{*} \\
\text { (s) }\end{array}$ & $\begin{array}{l}\text { Mucoadhesive } \\
\text { force } \pm S D^{*}(\mathrm{~N})\end{array}$ & $\begin{array}{l}\text { Viscosity } \\
(\mathrm{cP}) \text { at } 50 \\
\mathrm{RPM} \pm \mathrm{SD}^{*}\end{array}$ & $\begin{array}{l}\text { Cumulative } \% \\
\text { drug release at } 1^{\text {st }} \\
h \pm \mathrm{SD}^{*}\end{array}$ & $\begin{array}{l}\text { Cumulative } \% \\
\text { drug release at } \\
10^{\text {th }} \pm \mathrm{SD}^{*}\end{array}$ \\
\hline F1 & $05 \pm 0.47$ & $175 \pm 4.08$ & $6.86 \pm 2.31$ & $204 \pm 3.26$ & $12.15 \pm 0.11$ & $78.06 \pm 0.12$ \\
\hline $\mathrm{F} 2$ & $11 \pm 0.94$ & $020 \pm 1.63$ & $4.18 \pm 3.25$ & $043 \pm 1.24$ & $20.57 \pm 0.39$ & $95.32 \pm 0.64$ \\
\hline F3 & $04 \pm 0.94$ & $248 \pm 3.26$ & $7.61 \pm 3.76$ & $232 \pm 3.68$ & $17.79 \pm 0.68$ & $50.63 \pm 0.84$ \\
\hline F4 & $09 \pm 1.88$ & $035 \pm 2.05$ & $4.05 \pm 1.71$ & $055 \pm 2.16$ & $24.50 \pm 0.68$ & $61.19 \pm 0.72$ \\
\hline F5 & $05 \pm 1.41$ & $032 \pm 2.86$ & $6.45 \pm 2.43$ & $117 \pm 2.18$ & $30.75 \pm 0.63$ & $80.34 \pm 0.74$ \\
\hline F7 & $05 \pm 0.81$ & $064 \pm 3.29$ & $5.30 \pm 2.85$ & $136 \pm 2.86$ & $20.66 \pm 0.48$ & $67.02 \pm 0.74$ \\
\hline F8 & $09 \pm 0.81$ & $045 \pm 3.08$ & $4.35 \pm 3.97$ & $090 \pm 1.69$ & $25.56 \pm 0.57$ & $83.72 \pm 0.76$ \\
\hline
\end{tabular}

*Standard deviation $(\mathrm{n}=3)$

Table 4: ANOVA for response (gelation time)

\begin{tabular}{|c|c|c|c|c|c|c|c|}
\hline \multicolumn{8}{|c|}{ ANOVA for selected factorial model } \\
\hline \multicolumn{4}{|c|}{ Partial sum of squares-Type III } & \multicolumn{4}{|c|}{ Response: Gelation time (s) } \\
\hline Sourcemodel & Sum of squares & Df & Mean square & F value & $\mathbf{p}>\mathbf{F}$ & & \\
\hline Model & 125.17 & 7 & 17.88 & 10.47 & 0.0001 & & Significant \\
\hline A-gelrite & 60.17 & 1 & 60.17 & 35.22 & 0.0001 & & Significant \\
\hline B-Xanthan G & 24.00 & 1 & 24.00 & 14.05 & 0.0018 & & Significant \\
\hline C-HPMC E50 & 32.67 & 1 & 32.67 & 19.12 & 0.0005 & & Not Significant \\
\hline $\mathrm{AC}$ & 2.67 & 1 & 2.67 & 1.56 & 0.2295 & & Not Significant \\
\hline $\mathrm{BC}$ & 1.50 & 1 & 1.50 & 0.88 & 0.3627 & & Not Significant \\
\hline $\mathrm{ABC}$ & 1.50 & 1 & 1.50 & 0.88 & 0.3627 & & Not significant \\
\hline Pure error & 27.33 & 16 & 1.71 & & & & \\
\hline Cor total & 152.50 & 23 & & & & & \\
\hline SD & 1.31 & & & R-squared & & 0.8208 & \\
\hline Mean & 6.75 & & & Adj R-squared & & 0.7423 & \\
\hline CV \% & 19.36 & & & Pred R-squared & & 0.5967 & \\
\hline
\end{tabular}

Gelation time $=6.75-1.58 * \mathrm{~A}-1.00^{*} \mathrm{~B}-1.17^{*} \mathrm{C}+0.33^{*} \mathrm{~A}^{*} \mathrm{~B}+0.33^{*} \mathrm{~A}{ }^{*} \mathrm{C}-0.25{ }^{*} \mathrm{~B} * \mathrm{C}+0.25 * \mathrm{~A}^{*} \mathrm{~B} * \mathrm{C}$. HPMC: Hydroxypropyl methyl cellulose, CV: Curriculum vitae, SD: Standard deviation 
Table 5: ANOVA for response (gel strength)

\begin{tabular}{|c|c|c|c|c|c|c|c|}
\hline \multicolumn{8}{|c|}{ ANOVA for selected factorial model } \\
\hline \multicolumn{6}{|c|}{ Partial sum of squares-Type III } & \multicolumn{2}{|c|}{ Response: Gel strength (s) } \\
\hline Source model & Sum of squares & & df & Mean square & F value & $p>F$ & \\
\hline Model & $1.443 \mathrm{E}+005$ & & 7 & 20614.83 & 1446.65 & 0.0001 & Significant \\
\hline A-gelrite & 59401.50 & & 1 & 59401.50 & 4168.53 & 0.0001 & Significant \\
\hline B-Xanthan G & 43010.67 & & 1 & 43010.67 & 3018.29 & 0.0001 & Significant \\
\hline C-HPMC & 3504.17 & & 1 & 3504.17 & 245.91 & 0.0001 & Significant \\
\hline $\mathrm{AB}$ & 32560.67 & & 1 & 32560.67 & 2284.96 & 0.0001 & Significant \\
\hline $\mathrm{AC}$ & 3313.50 & & 1 & 3313.50 & 232.53 & 0.0001 & Significant \\
\hline $\mathrm{BC}$ & 192.67 & & 1 & 192.67 & 13.52 & 0.0020 & Significant \\
\hline $\mathrm{ABC}$ & 2320.67 & & 1 & 2320.67 & 162.85 & 0.0001 & Significant \\
\hline Pure error & 228.00 & & 16 & 14.25 & & & \\
\hline Cor total & $1.445 \mathrm{E}+005$ & & 23 & & & & \\
\hline SD & & 3.77 & & & R-squared & & 0.9984 \\
\hline Mean & & 82.58 & & & Adj R-squared & & 0.9977 \\
\hline CV \% & & 4.57 & & & Pred R-squared & & 0.9965 \\
\hline PRESS & & 513.00 & & & Adeq precision & & 104.614 \\
\hline
\end{tabular}

Gel strength $=82.58+49.75^{*} \mathrm{~A}+42.33^{*} \mathrm{~B}+12.08^{*} \mathrm{C}+36.83^{*} \mathrm{AB}+11.75^{*} \mathrm{AC}+2.83^{*} \mathrm{BC}+9.83^{*} \mathrm{~A}^{*} \mathrm{~B}^{*} \mathrm{C}$. HPMC: Hydroxypropyl methyl cellulose, CV: Curriculum vitae, SD: Standard deviation

Table 6: ANOVA for response (mucoadhesive force)

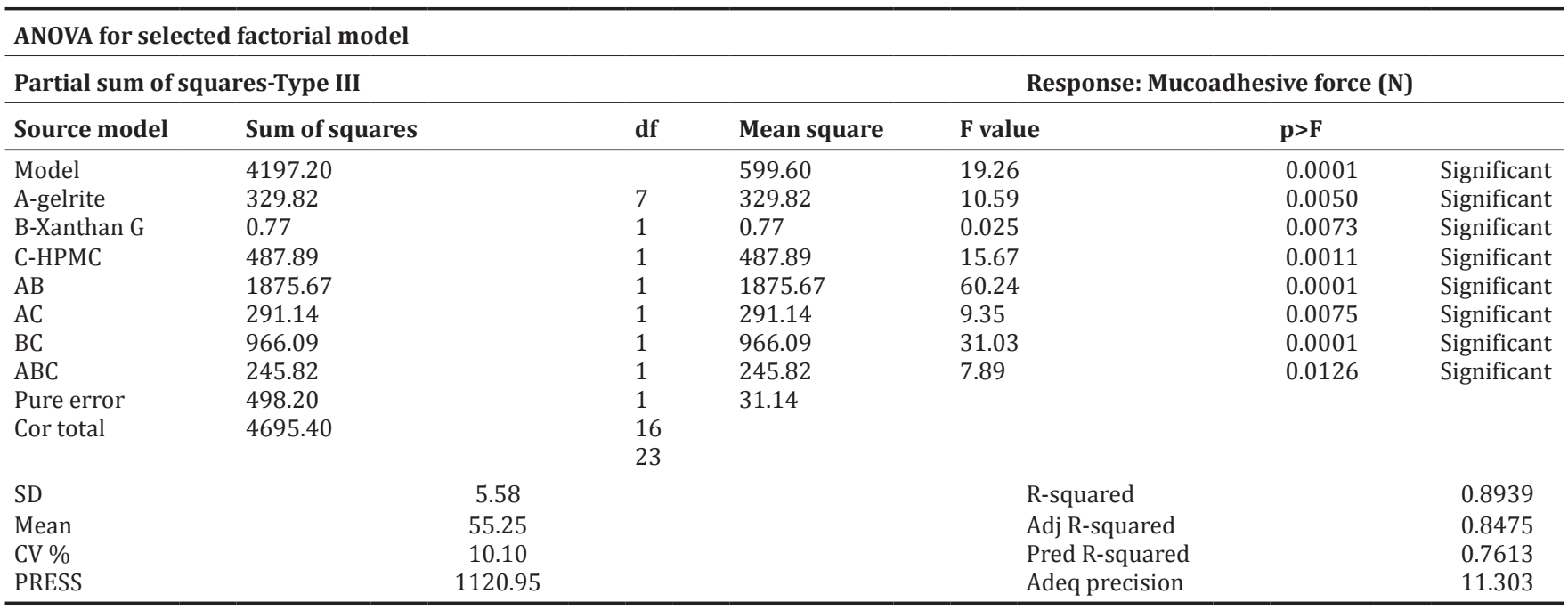

Mucoadhesive force $=55.25+3.71^{*} \mathrm{~A}+0.18^{*} \mathrm{~B}+4.51^{*} \mathrm{C}+8.84^{*} \mathrm{~A}^{*} \mathrm{~B}-3.48^{*} \mathrm{~A}^{*} \mathrm{C}-6.34^{*} \mathrm{~B}^{*} \mathrm{C}+3.20^{*} \mathrm{~A}^{*} \mathrm{~B}{ }^{*} \mathrm{C}$. HPMC: Hydroxypropyl methyl cellulose, CV: Curriculum vitae, SD: Standard deviation

Table 7: ANOVA for response (viscosity before gel at 50 RPM): Batch No II

\begin{tabular}{|c|c|c|c|c|c|c|}
\hline \multicolumn{7}{|c|}{ ANOVA for selected factorial model } \\
\hline \multicolumn{4}{|c|}{ Partial sum of squares-Type III } & \multicolumn{3}{|c|}{ Response: Viscosity before gel at $50 \mathrm{RPM}$} \\
\hline Source model & Sum of squares & df & Mean square & F value & $\mathbf{p}>\mathbf{F}$ & \\
\hline Model & $1.089 \mathrm{E}+005$ & 7 & 15550.47 & 1588.13 & $<0.0001$ & Significant \\
\hline A-gelrite & 36895.04 & 1 & 36895.04 & 3768.00 & $<0.0001$ & Significant \\
\hline B-xanthan gum & 49232.04 & 1 & 49232.04 & 5027.95 & $<0.0001$ & Significant \\
\hline C-HPMC & 9322.04 & 1 & 9322.04 & 952.04 & $<0.0001$ & Significant \\
\hline $\mathrm{AB}$ & 7957.04 & 1 & 7957.04 & 812.63 & $<0.0001$ & Significant \\
\hline $\mathrm{AC}$ & 2380.04 & 1 & 2380.04 & 243.07 & $<0.0001$ & Significant \\
\hline $\mathrm{BC}$ & 805.04 & 1 & 805.04 & 82.22 & $<0.0001$ & Significant \\
\hline $\mathrm{ABC}$ & 2262.04 & 1 & 2262.04 & 231.02 & $<0.0001$ & Significant \\
\hline Pure error & 156.67 & 16 & 9.79 & & & \\
\hline Cor total & $1.090 \mathrm{E}+005$ & 23 & & & & \\
\hline SD & 03. & & & R-squared & 0.9986 & \\
\hline Mean & 115 & & & Adj R-squared & 0.9979 & \\
\hline CV \% & 02.7 & & & Pred R-squared & 0.9968 & \\
\hline PRESS & 352 & & & Adeq precision & 104.615 & \\
\hline
\end{tabular}

Viscosity before gel=115.46+39.21*A+45.29*B+19.71* $\mathrm{C}+18.21^{*} \mathrm{~A}^{*} \mathrm{~B}+9.96^{*} \mathrm{~A}^{*} \mathrm{C}-5.79{ }^{*} \mathrm{~B} * \mathrm{C}-9.71^{*} \mathrm{~A}^{*} \mathrm{~B}{ }^{*} \mathrm{C}$. HPMC: Hydroxy propyl methyl cellulose, CV: Curriculum vitae, SD: Standard deviation 
Table 8: ANOVA for response (cumulative drug release $(\%) 10^{\text {th }} h$ )

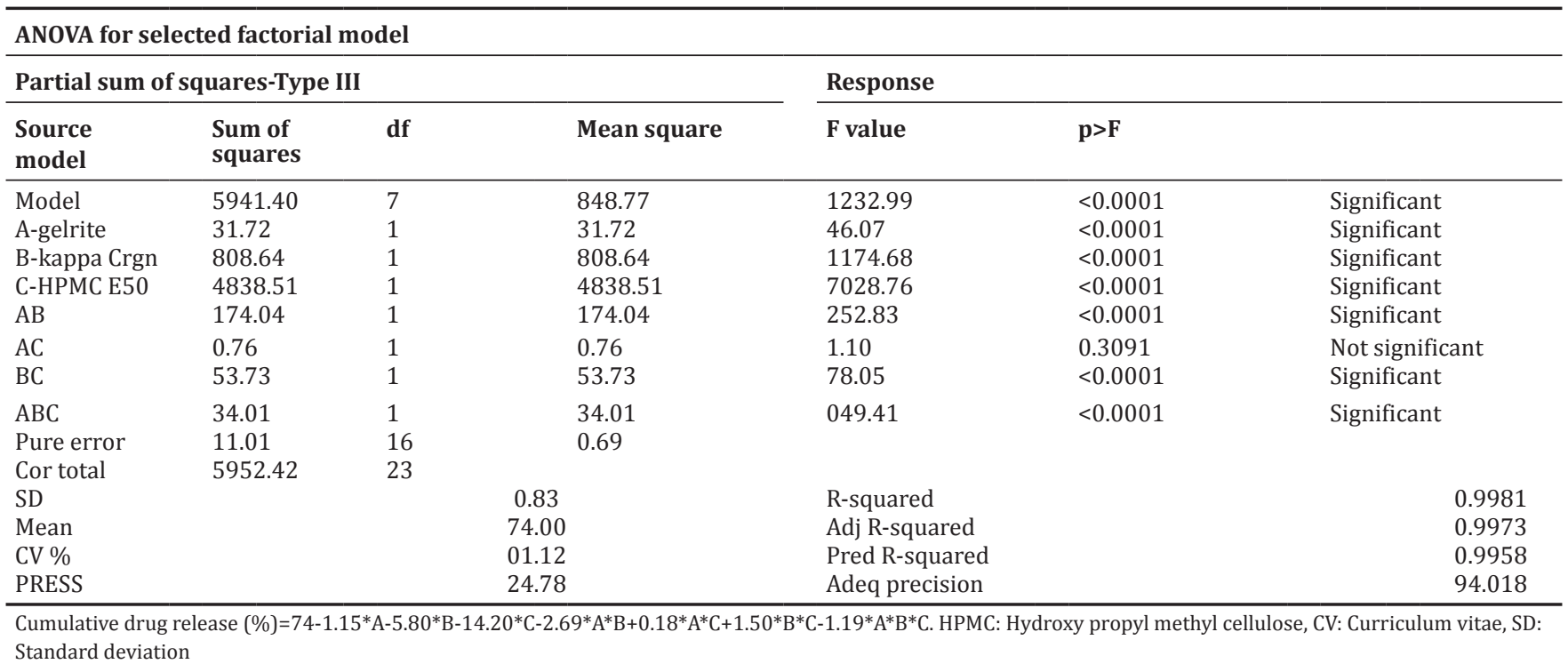

Table 9: Predicted and experimental observed responses of the optimized formulation with \% prediction error

\begin{tabular}{|c|c|c|c|c|c|c|c|c|c|}
\hline Number & Gelrite & $\begin{array}{l}\text { Xanthan } \\
\text { Gum }\end{array}$ & $\begin{array}{l}\text { HPMC } \\
\text { E50 }\end{array}$ & $\begin{array}{l}\text { Gelation } \\
\text { time }\end{array}$ & $\begin{array}{l}\text { Gel } \\
\text { strength }\end{array}$ & $\begin{array}{l}\text { Mucoadhesive } \\
\text { force }\end{array}$ & $\begin{array}{l}\text { Viscosity before } \\
\text { gel at } 50 \mathrm{RPM}\end{array}$ & $\begin{array}{l}\text { In vitro release } \\
\text { at } 10 \mathrm{~h}\end{array}$ & Desirability \\
\hline \multicolumn{10}{|c|}{ Predicted value } \\
\hline \multicolumn{10}{|c|}{ Observed value } \\
\hline 2 & 0.40 & 0.21 & 0.24 & 06.86 & 51.94 & 46.31 & 55.20 & 92.45 & \\
\hline & & & & 04.08 & 03.75 & 2.00 & 0.543 & 02.33 & \\
\hline
\end{tabular}

HPMC: Hydroxypropyl methyl cellulose

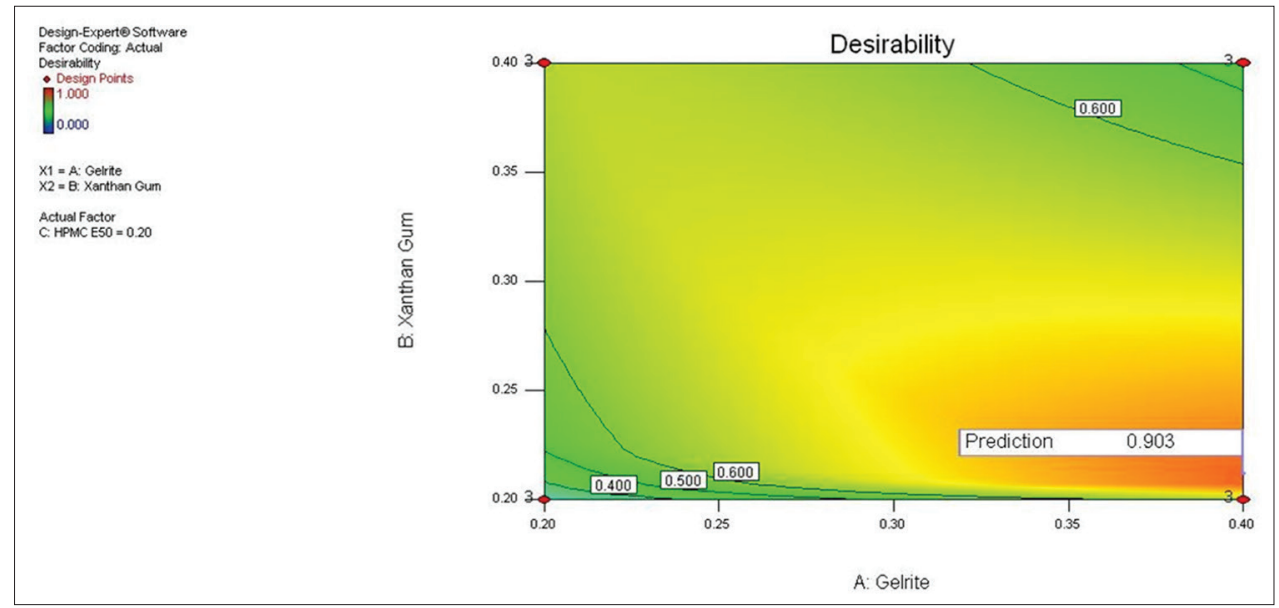

Fig. 1: Overlay graph of formulation optimization highlighting an area of operability

experimental values for each response were calculated, and the values found to be within $5 \%$. The experimental values were in agreement with the predicted values, confirming the predictability and validity of the optimization process. In vitro release studies showed that HPMC E50 LV acts as release retardant. From the kinetic study, it was found the drug release from the optimized formulation followed first-order kinetics, since a straight line was obtained. From Higuchi plots, the plots were found to be linear which indicates the drug release from the in situ gel was by diffusion. The " $n$ " values obtained from the Peppas equation were $<0.5$, which indicates the drug release by fickian diffusion mechanism.
The $\mathrm{pH}$ of formulations was within the range of comfort (6.8-7.8); hence, formulation will be tolerated by the eyes. Solutions showed less percentage transmittance because of the presence of polymers. Formed gels (mixing with STF (pH 7.4) showed greater percentage transmittance compared to solutions. Gels with optical transmission $\geq 90 \%$ are termed as transparent, $\leq 90 \%$ but $\geq 10 \%$ as translucent, and $\leq 10 \%$ as opaque. The study reveals that in situ gels were translucent. The sol-gel is dropped in the cul-de-sac where it forms a gel, the so formed gel will not spread over the eye (Table 10). Rheological studies manifested that the shear stress and viscosity at $37^{\circ} \mathrm{C}$ with STF were higher than those at $25^{\circ} \mathrm{C}$ without STF. It was noted from the various 
literature that the solution before gelling should have a viscosity of 5-1000 cPs and after gelling in the eye a viscosity from about 50 to $50,000 \mathrm{cPs}$. The ocular shear rate is about $0.03 / \mathrm{s}$ during inter-blinking periods and 4250-28500/s during blinking. The viscosity of the solution ranged from 27 to $351 \mathrm{cps}$ before gelation and 300 to $675 \mathrm{cP}$ after gelation. Viscoelastic fluids having high viscosity under low shear rates and low viscosity under high shear rates, i.e., pseudo plastic fluid is often preferred. This may favor the sustained release of drug in the conjunctival sac of the eye and also without much blinking difficulty for shear thinning.

The formulation incubated with media suitable for the growth and proliferation of aerobic/anaerobic bacteria, fungi showed no growth at the end of 14 days at $35^{\circ} \mathrm{C}$ and at $25^{\circ} \mathrm{C}$. No evidence of microbial growth/turbidity was found in the test and negative samples when compared with positive control media. This indicated that formulations were free from micro-organisms; which also proved the effectiveness of moist heat sterilization. Hence, the preparations being examined

Table 10: Composite evaluation parameter of optimized formulation

\begin{tabular}{lll}
\hline S. No & Evaluation parameters & Optimized formulation \\
\hline 1 & pH & $7.46 \pm 0.094$ \\
2 & Clarity (before gel) & 44 \\
3 & Clarity (after gel) & 84 \\
4 & Mucoadhesive force & $46.50 \pm 3.48$ \\
5 & Viscosity before gel at $50 \mathrm{RPM}$ & $192 \pm 04.89$ \\
6 & In vitro drug release at $10^{\text {th }} \mathrm{h}$ & $88.69 \pm 3.21$ \\
7 & Isotonicity & Isotonic \\
8 & Ocular tolerance & Non-irritant \\
9 & Sterility test & Sterile \\
10 & Ocular visualization of in situ gels & Easy to instill \\
\hline
\end{tabular}

*SD (n=3). SD: Standard deviation
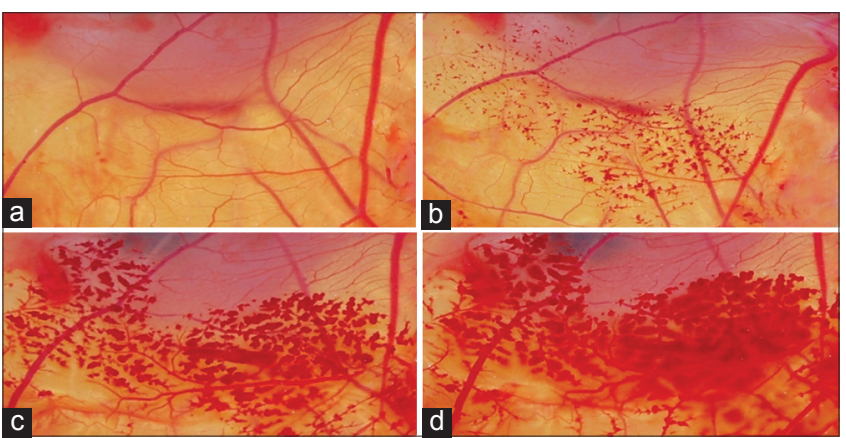

Fig. 2: (a) Membrane with $0.1 \% \mathrm{NaoH}$ at $0 \mathrm{~min},(\mathrm{~b}) \mathrm{NaOH}$ at 0.5 min,(c) $\mathrm{NaOH}$ at $2 \mathrm{~min}$, and (d) $\mathrm{NaOH}$ at $5 \mathrm{~min}$

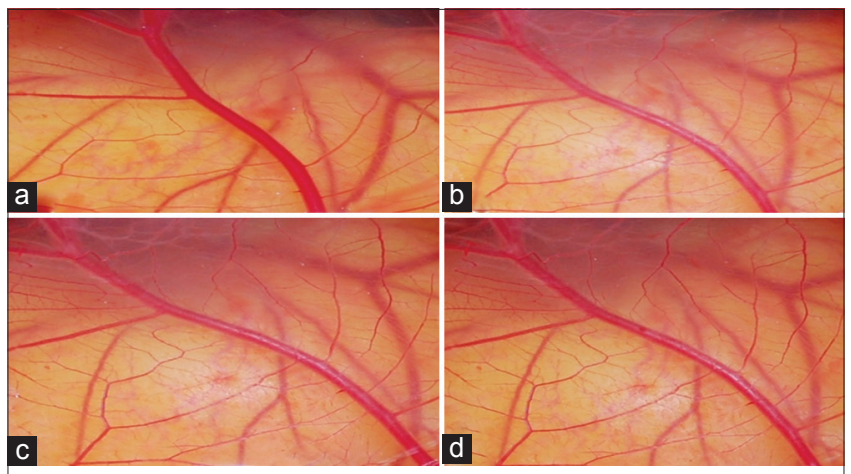

Fig. 3: (a) Membrane with $0.9 \% \mathrm{Nacl}$ at $0 \mathrm{~min}$, (b) Nacl at $0.5 \mathrm{~min}$, (c) Nacl at $2 \mathrm{~min}$, and (d) Nacl at $5 \mathrm{~min}$ complies with the test for sterility (Table 10). Formulation showed no changes in size and shape of RBC (neither hypertonic nor hypotonic). This qualitative study showed that formulations are isotonic with blood (Table 10).

Formulations scoring were compared with those obtained using normal saline, $0.1 \mathrm{~N} \mathrm{NaOH}$ as controls. A means score of 0 was obtained for normal saline as well as for in situ gel-based formulation up to $5 \mathrm{~min}$ and no change was seen after $5 \mathrm{~min}$ also. The scoring for $0.1 \mathrm{~N} \mathrm{NaOH}$ found to be $15.00 / 10.20$. The study shows that the formulation was non irritant, as results obtained by HET-CAM and those of the positive and negative controls (Figs. 2-4).

Ocular visualization showed that in situ gels were quickly formed when it comes in contact with the lachrymal fluid. Hence, it is easy to instill in the eye (Fig. 5).

\section{CONCLUSION}

An in situ gel-forming BT/xanthan gum eye drop using gellan gum as an ion-activated polymer was developed. The application of experimental design methodology helped to prepare the optimized formulation, which showed appropriate mucoadhesive force and in vitro percentage drug release. From the factorial design, the optimum concentrations of gelrite, HPMC E50 LV, and xanthan gum as mucoadhesive for the in situ ocular drug delivery system were $0.4 \%, 0.21 \%$, and $0.24 \%$ $(\mathrm{w} / \mathrm{v})$, respectively. FTIR spectroscopy study reveals no significant interaction between drug and polymers. Hence, it is concluded that the drug to be compatible with polymers, ocular visualization showed optimized formulation showed evidence of phase transition and in situ gel structure formation on contact with cations of the STF. The in situ gel-formed was viscoelastic in nature and sustained the drug release for $10 \mathrm{~h}$. The drug release from the in situ gel formed was by diffusion from the gel matrix. Formulation to be sterile ocular irritation studies showed the absence of hyperemia, hemorrhage, and coagulation. We can conclude that an optimized formulation was non irritant, as results obtained by HET-CAM and with those of the positive and negative controls. Ocular visualization showed optimized formulation showed evidence of phase transition and in situ gel structure formation on

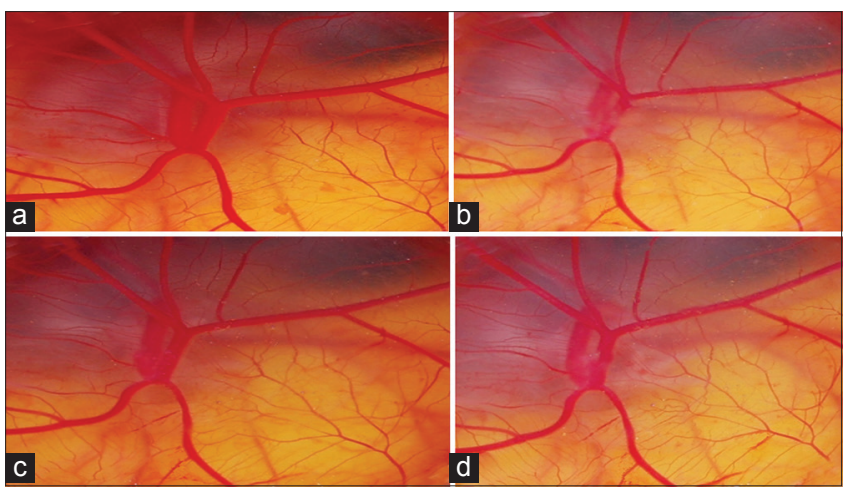

Fig. 3: (a) Membrane with $0.9 \% \mathrm{Nacl}$ at $0 \mathrm{~min}$, (b) Nacl at $0.5 \mathrm{~min}$ (c) Nacl at $2 \mathrm{~min}$, and (d) Nacl at $5 \mathrm{~min}$

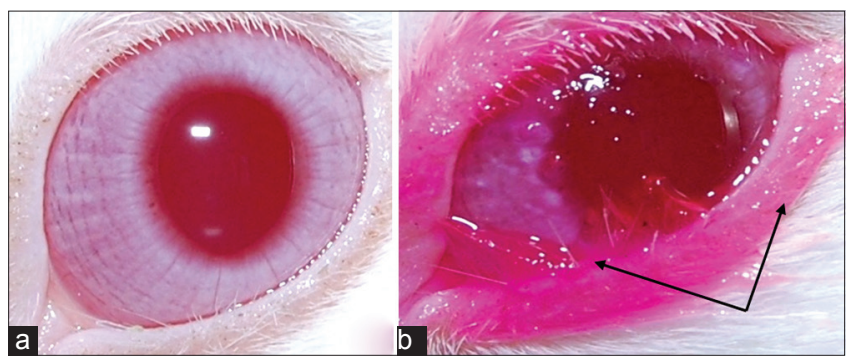

Fig. 5: (a) Normal rabbit left eye (LE) (b): Formulation F2 (colored gel formation) with Rhodamine B dye (LE) 
contact with cations of the STF. The effect of combining a mucoadhesive polymer to gelrite showed its ability to enhance bioavailability through its greater mucoadhesive strength which indicates longer precorneal residence time and also promises to reduce the frequency of drug administration, thus improving patient compliance.

\section{AUTHORS' CONTRIBUTION}

Contribution of all authors is equal.

\section{CONFLICTS OF INTEREST}

Authors do not have any conflicts of interest to disclose.

\section{REFERENCES}

1. Manish K, Kulkarni GT. Recent advances in ophthalmic drug delivery system. Int J Pharm Pharm Sci 2012;1:387-94.

2. Gupta S, Rajesh KS. Ophthalmic drug delivery systems with emphasis on in-situ hydrogels. Pharmagene 2013;1:80-7.

3. Ceulemans J, Vinckier I, Ludwig A. The use of xanthan gum in an ophthalmic liquid dosage form: Rheological characterization of the interaction with mucin. J Pharm Sci 2002;91:1117-27.

4. Bawa R, Hall RE, Kabra BP, Teague JE, Cagle GD, Markwardt KL, Shah MV. Gelling Ophthalmic Compositions Containing Xanthan Gum US.PATENT 6,261,547; 2001.

5. Deshmukh PK, Gattani SG. In vitro and in vivo consideration of novel environmentally responsive ophthalmic drug delivery system. Pharm Dev Technol 2013;18:950-6.

6. Chastaing G, Beaumont FR, Plazonnet B, Ferrand C, Rozier A. Ophthalmic Composition Containing a Carbonic Anhydrase Inhibitor and Xanthan Gum. US.PATENT 6,264,935; 2001.

7. Nayak SN, Sogali BS, Thakur RS. Formulation and evaluation of ph triggered in situ ophthalmic gel of moxifloxacin hydrochloride in-situ gelling system. Int J Pharm Pharm Sci 2012;4:452-9.

8. Dyer JR. Application of Absorption Spectroscopy of Organic Compounds. $8^{\text {th }}$ ed. New Delhi: Prentice Hall Learning; 1991.

9. Kumar JR, Muralidharan S. Development of microparticle loaded gel (MPLGs) for prolong ocular drug delivery containing ketorolac tromethamine. J Pharm Sci Res 2014;6:148-52.

10. Kanoujia J, Sonker K, Pandey M, Koshy M, Shubhini AK, Saraf SA. Formulation and characterization of a novel $\mathrm{pH}$-triggered in-situ gelling ocular system containing Gatifloxacin. Int Curr Pharm J 2012;1:43-9.

11. Dasankoppa FS, Solankiy P, Sholapur HN, Jamakandi VG, Sajjanar VM, Walveka PM. Formulation and evaluation of a novel in situ gum base ophthalmic drug delivery system of linezolid. Sci Pharm 2008;76:51532.

12. Farheen T, Sadhana RS, Shaikh AM, Zudbuke N, Ali SA. Formulation development and evaluation of in-situ ophthalmic gel of sodium cromoglycate. Der Pharm Sin 2013;4:109-18.

13. Franklin KR, Kowalski AJ, Marie Esser ICH, Rowe KE. Antiperspirant Compositions US.PATENT 2000061082; 2000.

14. Dave V, Paliwal S, Yadav S, Sharma S. Effect of in vitro transcorneal approach of aceclofenac eye drops through excised goat, sheep, and buffalo corneas. Sci World J 2015;2015:1-7.

15. Kumar K, Mishra IN, Sandhya J. Study of storage periods of culture suspension of Escherichia coli. Int J Pharma Sci Drug Res 2013;5:36-7.

16. Smith R, von Tress M, Tubb C, Vanhaecke E. Evaluation of the scanRDI as a rapid alternative to the pharmacopoeial sterility test method: Comparison of the limits of detection. J Pharm Sci Tech 2010;64:356-63.

17. Sterility Testing: Pharmaceutical Products. Available from: http://www. newagepublishers.com/sample chapter.pdf. [Last cited 2016 Feb].

18. General Requirements For The Sterility Of Biological Substance. Available from: http://www.who.int/biologicals/publications/sterility/ WHO_TRS_530_A4.pdf. [Last cited 2016 Feb].

19. Pharmaceutical Microbiology and Biotechnology. Available from: http://www.nsdl.niscair.res.in/sterilization methods and Principles.pdf. [Last cited 2016 Feb].

20. Current Status of In Vitro Test Methods for Identifying Ocular Corrosives and Severe Irritants: Hen's Egg Test-Chorioallantoic Membrane Test Method. Available from: http://www.iccvam.niehs.nih. gov/methods/ocudocs/ocu brd.htm\#hetcam. [Last cited 2015 Aug]

21. Day 9 Of Incubation: The Story Inside The Chicken Egg. Available from: http://www.raising-happy-chickens.com/incubation-day-9.html. [Last cited 2015 Aug].

22. Guss R, Johnson R, Maurice D. Rhodamine B as a test molecule in intraocular dynamics. Invest Ophthalmol Vis Sci 1984;25:758-62 